
October 1936

\title{
DIFFERENCE IN ATOMIC WEIGHT OF OXYGEN FROM AIR AND FROM WATER
}

\author{
By Edgar R. Smith and Harry Matheson
}

\begin{abstract}
The hydrogen in ordinary water and that in water formed by burning commercial electrolytic hydrogen with atmospheric oxygen were brought to the same isotopic composition by equilibration with ammonia. The water containing atmospheric oxygen was then found to have a density greater by $8.6 \mathrm{ppm}$ than that of the water containing aqueous oxygen. By this method of preparing two samples of water, which differ only with respect to the isotopic composition of their oxygen content, the use of electrolysis, with its attendant possibility of slight changes due to electrolytic fractionation, in the relative isotopic composition of the oxygen, is eliminated. The magnitude of the difference in density was also confirmed by an independent method. This involved the utilization of hydrogen and oxygen, having practically the same isotopic composition as in normal water, which are evolved after prolonged electrolysis until an equilibrium state is attained in a small commercial electrolyzer. A comparison of the water formed by burning together the electrolyzed hydrogen and atmospheric oxygen with the water formed by recombining the gases from the electrolyzer again yields the difference between atmospheric and aqueous oxygen. This difference is also obtained by comparison of the water formed by burning together tank hydrogen and atmospheric oxygen with the water formed by burning hydrogen from the same tank with oxygen from the electrolyzer. The measured difference in density corresponds to a difference of $0.0001_{4}$ atomic weight unit between the atomic weights of atmospheric and aqueous oxygen.
\end{abstract}

A surprising difference between the isotopic composition of normal atmospheric oxygen and oxygen in normal water was discovered independently by Dole ${ }^{1}$ and by Morita and Titani. ${ }^{2}$ Dole first combined oxygen of the air with commercial hydrogen. Then, since the hydrogen of this water differed in atomic weight from the hydrogen of normal water, samples of both this water and normal water were electrolyzed by approximately the same fractional amount and both oxygens converted again to water with hydrogen from a single tank. In this way, the density of water made from tank hydrogen and oxygen originally from the air could be compared with the density of water made from the same tank hydrogen and oxygen originally from Lake Michigan water. As a result of two series of measurements, the difference in density between water made with oxygen of the air and water made with aqueous oxygen was found to be $6.0 \pm 0.6 \mathrm{ppm}$. By fractional electrolysis of water, Morita and Titani prepared hydrogen having a deuterium content of less than 1 atom in 30,000. This light hydrogen was combined separately with oxygen of the air and with oxygen obtained from water by electrolyzing 95 percent of the initial water. The density of the water made with oxygen from the air was

1 M. Dole, J. Am. Chem. Soc. 57, 2731 (1935); 58, 580 (1936); J. Chem. Phys. 4, 268 (1936)

2 N. Morita and T. Titani, Bul. Chem. Soc. Japan 11, 36 and 414 (1936). 
found to be greater by $8 \pm 2$ and $7 \pm 1 \mathrm{ppm}$ than that of the water made with aqueous oxygen. Greene and Voskuyl ${ }^{3}$ have reported differences of 5.8 and $6.2 \mathrm{ppm}$ in two experiments in which the densities of protium oxide with atmospheric oxygen and protium oxide with aqueous oxygen were compared. However, they did not publish the details of their technic.

The results of all these investigations, with the possible exception of those of Greene and Voskuyl, are not entirely free from the objection that the fractionation of the oxygen isotopes which occurs on electrolysis may possibly produce variations of 1 or $2 \mathrm{ppm}$ in the densities of the resulting preparations if the conditions of electrolysis in the parallel experiments are not exactly the same. For this reason, and because a difference in density of 5 or more ppm between water with atmospheric oxygen and water with aqueous oxygen corresponds to a significant difference of 0.0001 or more in the atomic weights of atmospheric and aqueous oxygen, it seemed important to prepare for comparison, without resort to electrolysis, two samples of water, identical with respect to hydrogen, one with atmospheric oxygen and the other with aqueous oxygen.

For this direct comparison, about $500 \mathrm{ml}$ of water was prepared by combining dried atmospheric oxygen with tank hydrogen. ${ }^{4}$ The density of the water thus prepared was $1.2 \mathrm{ppm}$ greater than that of normal water. This water was then saturated and desaturated successively four times with dried ammonia. ${ }^{5}$ The same volume of normal water, having the Potomac River as its source, was then saturated and desaturated successively twice with the same tank ammonia. $^{6}$ By this treatment the hydrogen of both waters was brought to the same isotopic composition, and any difference in density would be due to a difference in the isotopic composition of atmospheric and aqueous oxygen. After purification, the water containing atmospheric oxygen was found to have a density greater by $8.5 \mathrm{ppm}$ at $25^{\circ} \mathrm{C}$ than that of the water containing aqueous oxygen. The density measurements were made by the twin quartz pycnometer method which has been described in detail. ${ }^{8}$ Following this first determination, both waters were subjected to two more successive saturations and desaturations and, after purification, were found to differ again in the same way in density by $8.7 \mathrm{ppm}$. The average of the two results is $8.6 \mathrm{ppm}$. The use of anhydrous ammonia as an equilibrating agent for the hydrogen of water is rapid and effective, as was first shown by Lewis, ${ }^{9}$ and in the present case permits the direct measurement of the difference in density due to the difference in oxygen alone, and eliminates electrolytic fractionation. The agreement of the two determinations shows that equilibrium with the ammonia had been attained. In using this method it is assumed, of course, that the exchange of deuterium and hydrogen

3 C. H. Greene and R. J. Voskuyl, J. Am. Chem. Soc. 58, 693 (1936)

4 . Dole, Loc. cit., has shown that no measurable fractionation of the oxygen isotopes occurs during combustion.

5 In some unpublished work done in this laboratory it has been found that after ammonia is absorbed by water having a larger proportion of deuterium than normal, until the total volume is approximately doubled while the container is immersed in a cooling mixture, and then the ammonia is expelled, the deuterium content of the water is reduced by about 45 percent each time the cycle is performed. This is the procedure referred to as saturation and desaturation with ammonia.

6 Previous work had shown that the hydrogen of this ammonia and of ordinary water have practically the same isotopic composition.

7 E. W. Washburn and E. R. Smith, BS J. Research 12, 305 (1934) R P656.

8 E. R. Smith and M. Wojciechowski, Roczniki Chem. 16, 104 (1936); Bul. int. acad. polonaise (A) March (1936)

G. N. Lewis, J. Am. Chem. Soc. 55, 3502 (1933). 
between ammonia and water is independent of the kind of oxygen present.

An interesting, although not very accurate, confirmation of the density difference in question was obtained in the following way. A commercial electrolyzer of the filter-press type, having 56 nickelplated cast-iron cells in series, and a capacity of 16 liters, was filled with alkaline solution from the large commercial cells of the Southern Oxygen Company, South Washington, Va. The solution was electrolyzed continuously, on a 24 -hour day basis, with the addition of normal water in $250-\mathrm{ml}$ portions to keep practically constant the level in the electrolyzer, until the water formed by recombining the electrolyzed gases did not differ in density from normal water by more than $1 \mathrm{ppm}$. In this state the gases evolved have practically the same isotopic composition as in the normal water added to the cell, ${ }^{10}$ so that the hydrogen from the electrolyzer, $\mathrm{H}^{\mathrm{E}}$, is practically identical with the hydrogen from normal water, $\mathrm{H}^{\mathrm{w}}$, and oxygen from the electrolyzer, $\mathrm{O}^{\mathrm{E}}$, is almost the same as the oxygen in normal water, $\mathrm{O}^{\mathrm{w}}$, i. e. $\mathrm{H}^{\mathrm{E}} \cong \mathrm{H}^{\mathrm{w}}$ and $\mathrm{O}^{\mathrm{E}} \cong \mathrm{O}^{\mathrm{w}}$. At this stage, hydrogen from the electrolyzer was burned with dried atmospheric oxygen, $\mathrm{O}^{\mathrm{A}}$, to form water which may be designated as $\mathrm{H}_{2}{ }_{2} \mathrm{O}^{\mathrm{A}}$. The combustions were made with a gas burner inclosed in a flame hood connected to a condenser. After purification, the density of this water was found to be greater than that of $\mathrm{H}_{2}{ }_{2} \mathrm{O}^{\mathrm{E}}$ by 9.7 and $9.6 \mathrm{ppm}$ in two determinations with intervening distillation of both preparations. This difference should approximate that between two samples of water, one containing atmospheric oxygen, the other aqueous oxygen, and both with the same hydrogen.

Hydrogen from a certain tank was also burned with atmospheric oxygen to form $\mathrm{H}_{2}{ }_{2} \mathrm{O}^{\mathrm{A}}$, and with oxygen from the electrolyzer to form $\mathrm{H}^{\mathrm{T}}{ }_{2} \mathrm{O}^{\mathrm{E}}$. The density of $\mathrm{H}^{\mathrm{T}} \mathrm{O}_{2}{ }^{\mathrm{A}}$ was found to be greater than that of $\mathrm{H}^{\mathrm{T}_{2}} \mathrm{O}^{\mathrm{E}}$ by 7.4 and $7.9 \mathrm{ppm}$ in two determinations with intervening distillation of both preparations. This difference should also approximate the value under investigation. The average of the differences, 9.7, 9.6, 7.4 and $7.9 \mathrm{ppm}$, found in the work with the electrolyzer filled with "equilibrium" water is $8.7 \mathrm{ppm}$. The close agreement between this average and the more precisely measured value of $8.6 \mathrm{ppm}$ obtained by the direct method of equilibrating the hydrogens is obviously fortuitous, since the level of electrolyte in the electrolyzer can be kept only approximately constant and small fluctuations in the isotopic composition of the gases evolved is unavoidable. However, the order of magnitude of the difference is confirmed, and the value of $8.6 \mathrm{ppm}$ is believed to be accurate to within $1 \mathrm{ppm}$.

All results reported up to the present time are summarized in table 1. The discrepancy of about $2 \mathrm{ppm}$ between the values reported by Dole, and by Greene and Voskuyl; and those reported by Morita and Titani, and in the present work, is apparently greater than the experimental error involved in the determination of density. It is also greater than the variation to be expected in normal water from different locations, since even the difference between water from the ocean and normal water from different places is only about

\footnotetext{
${ }^{10}$ This is an assumption, since the possibility remains that one, e. g., hydrogen, is lighter and the other, ө. g., oxygen, is heavier than normal, the combination yielding water of normal density.
} 
2 ppm. ${ }^{11} 1213$ Lake Michigan water was found by Greene and Voskuyl to have the same density as Cambridge, Massachusetts, tap water, and the difference in density between Atlantic Ocean water and Cambridge water is the same as between Atlantic Ocean water and Potomac River water. These results show indirectly that Lake Michigan water is the same as Potomac River water. The average of the mean values reported by all investigators is about $7 \mathrm{ppm}$, and in view of the fact that the value found in this investigation was obtained by a more direct method, it may be best at the present time to adopt a value of $8.0 \mathrm{ppm}$ as probably correct within $1 \mathrm{ppm}$. This difference in density is equivalent to a difference in the atomic weight of atmospheric oxygen and normal aqueous oxygen of $0.0001_{4}$ atomic weight unit.

TABLE 1.-Increase in density $(\Delta d)$ of water with atmospheric oxygen over water with aqueous oxygen

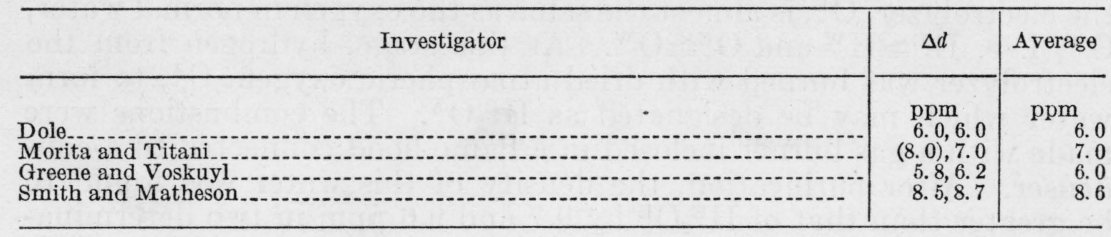

The authors desire to express their appreciation to Professor Malcolm Dole of Northwestern University for helpful comments on the manuscript of this paper.

Washington, August 15, 1936.

11 E. S. Gilfillan, J. Am. Chem. Soc. 56, 406 (1934).

12 C. H. Greene and R. J. Voskuyl, J. Am. Chem. Soc. 56, 1649 (1934)

13 E. W. Washburn and E. R. Smith, BS J. Research 12, 305 (1934) RP656. 